\title{
The Impact of High Temperature during Growing Season on Potato Cultivars with Different Response to Environmental Stresses
}

\author{
Krystyna Rykaczewska \\ Department of Potato Agronomy, Plant Breeding and Acclimatization Institute-NRI, Serock, Poland. \\ Email: k.rykaczewska@ihar.edu.pl
}

Received August $9^{\text {th }}, 2013$; revised October $1^{\text {st }}, 2013$; accepted November $5^{\text {th }}, 2013$

Copyright (C) 2013 Krystyna Rykaczewska. This is an open access article distributed under the Creative Commons Attribution License, which permits unrestricted use, distribution, and reproduction in any medium, provided the original work is properly cited.

\begin{abstract}
Potato crop is the fourth main food crops in the world after maize, rice and wheat. It is characterized by specific temperature requirements and develops best at about $20^{\circ} \mathrm{C}$. Forecasts of global warming prompt us to study the tolerance of potato genotypes to heat during the growing season. The aim of this work was to assess the response of chosen potato cultivars to high temperature during the different stages of plant growth under conditions of good soil moisture and drought. The impact of high temperature $32^{\circ} \mathrm{C} / 25^{\circ} \mathrm{C}$ on potato plants was determined in pot experiment in three growth stages. A main measure of tolerance of the potato cultivars to high temperature during the growing season was an evaluation of the yield in relation to the Control combination. Here we demonstrated that tested potato cultivar's response to high temperature during the growing season is dependent on the growth stage. The earlier it occurs, the more negative its impact on the growth and yield of potatoes is.
\end{abstract}

Keywords: Potato (Solanum tuberosum L); Heat Stress during Growing Period; Drought; Tuber Yield; Physiological Defects of Tubers

\section{Introduction}

Heat stress due to increased temperature is an agricultural problem in many areas in the world. Transitory or constant high temperatures cause an array of morphoanatomical, physiological and biochemical changes in plants, which affect plant growth and development and may lead to a drastic reduction in economic yield [1]. The adverse effects of heat stress can be mitigated by developing crop plants with improved thermotolerance using various genetic approaches. For this purpose, however, a thorough understanding of physiological responses of plants to high temperature is imperative.

Potato (Solanum tuberosum L) crop is the world's number one non-grain food commodity and the fourth main food crops in the world after maize, rice and wheat, with 324 million tons produced on the area of 19 million hectares in 2010 [2]. It is grown in more than 100 countries, mainly in Asia and Europe [3]. The potato is a plant mainly of typical temperate climate. The crop grows best in cool but frost-free seasons and does not perform well in heat $[4,5]$. It is characterized by specific temperature requirements. The limits and optimal values for the growth of the above-ground part of the potato plant and for the tubers are different. From experiments conducted in growth chambers it is known that haulm growth is fastest in the temperature range of $20^{\circ} \mathrm{C}-25^{\circ} \mathrm{C}$ whereas the optimal range for tuberization and tuber growth is $15^{\circ} \mathrm{C}-20^{\circ} \mathrm{C}$ [6-10]. At a temperature higher than optimal a reduction or complete inhibition of tuberization and the intensified development of aboveground part of plants take place. The negative impact of high temperatures on tuber yield is the result of the consumption of assimilates by intensively growing shoots.

In natural conditions drought and heat stress are two different types of abiotic stresses that occur generally in the field simultaneously. Several studies have examined the effects of a combination of these stresses on the growth and productivity of many crops. Mittler [11] found that a combination of drought and heat stress had a significantly greater detrimental effect on the growth and productivity of these plants and crops compared with each of the different stresses applied individually. Due to 
increasing irrigation use on potato plantations and periodic action of heat stress under conditions of good soil moisture, in some studies the impact of high temperature on potato plants was separated from the impact of drought [12-14]. According to De Temmerman et al. [15] it is not clear if the whole growing period is important for potato or if the time between maximum leaf area, coinciding with the stage of flowering and harvest, is the most sensitive period. Generally there is not much information on the effect of heat and drought stress at different stages of tuber growth [16]. Forecasts of global warming and periods of high temperature and drought becoming more frequent in Central Europe and also the need to export seed potatoes to countries with high temperatures in the summer prompt us to study the tolerance of potato genotypes to heat during the growing season.

The aim of this work was to assess the response of chosen potato cultivars to high temperature during the different stages of plant growth under soil moisture conditions favourable to plants and under drought conditions.

\section{Materials and Methods}

\subsection{Tested Cultivars and Treatments}

The pot experiment was carried out in open area next to the greenhouse and in a growth chamber, during two years. The following cultivars were tested: Irys (very early), Cyprian (early), Adam, Irga, Zebra (medium early) and the cultivar Katahdin (medium early) with very high adaptability to the environment [17]. The first five cultivars came from Polish Potato Breeding in Strzekęcin and the sixth from the Potato Gene Bank.

The impact of high temperature day/night $32^{\circ} \mathrm{C} / 25^{\circ} \mathrm{C}$ on potato plants was tested in three periods: I-June 1630, II-July 1-15 and III-July 16-30. In these periods half of the plants were watered to a level close to optimal (Favourable Soil Moisture), while the other half remained without irrigation (Soil Drought). The Control combination consisted of potato plants grown throughout the whole season under conditions close to optimal.

\subsection{Weather Conditions}

Weather conditions during the years of study were monitored using a Weather Campbell Station (Campbell Scientific Inc.) located right next to the greenhouse and additionally using a thermohigrograph placed between pots. The two most important meteorological factors, air temperature and the photosynthetically active radiation, were similar in the years of study and favourable for potato development (Table 1).

Table 1. Air temperature and photosynthetically active radiation (PAR) during growing season in the years of study.

\begin{tabular}{|c|c|c|c|c|c|c|c|c|c|}
\hline \multirow{2}{*}{ Meteorolgical factor } & \multirow{2}{*}{ Year } & \multirow{2}{*}{ Decade $^{*}$} & \multicolumn{6}{|c|}{ Month } & \multirow{2}{*}{ Mean } \\
\hline & & & April & May & June & July & August & Sept. & \\
\hline \multirow{8}{*}{$\begin{array}{c}\text { Temperature } \\
\text { in }{ }^{\circ} \mathrm{C}\end{array}$} & \multirow{5}{*}{2008} & I & 3.3 & 11.5 & 18.2 & 17.4 & 18.3 & 17.4 & \multirow{7}{*}{14.2} \\
\hline & & II & 7.7 & 12.7 & 15.5 & 17.6 & 19.2 & 8.4 & \\
\hline & & III & 10.5 & 15.5 & 17.5 & 19.3 & 15.7 & 9.0 & \\
\hline & & mean & 7.2 & 13.2 & 17.1 & 18.1 & 17.7 & 11.6 & \\
\hline & & I & 8.9 & 12.0 & 12.6 & 21.1 & 18.7 & 15.8 & \\
\hline & \multirow{3}{*}{2009} & II & 7.9 & 11.4 & 16.0 & 20.0 & 16.9 & 14.4 & \\
\hline & & III & 12.2 & 13.3 & 20.7 & 18.1 & 16.6 & 12.5 & \\
\hline & & mean & 9.7 & 12.2 & 16.4 & 19.7 & 17.4 & 14.2 & \multirow[t]{2}{*}{14.9} \\
\hline \multirow{8}{*}{$\begin{array}{l}\text { PAR in } \\
\mathrm{J}^{-1} \cdot \mathrm{sek}^{1}\end{array}$} & \multirow{4}{*}{2008} & I & 147 & 348 & 527 & 455 & 367 & 297 & \\
\hline & & II & 207 & 410 & 423 & 334 & 325 & 116 & \\
\hline & & III & 361 & 441 & 461 & 425 & 288 & 148 & \\
\hline & & mean & 268 & 412 & 470 & 405 & 325 & 187 & 344.5 \\
\hline & \multirow{4}{*}{2009} & I & 332 & 408 & 360 & 479 & 398 & 279 & \\
\hline & & II & 314 & 415 & 450 & 420 & 358 & 284 & \\
\hline & & III & 455 & 323 & 510 & 360 & 329 & 285 & \\
\hline & & mean & 367 & 380 & 440 & 420 & 361 & 282 & 375.0 \\
\hline
\end{tabular}

Explanation: "decade-10 days of the month: I-1 - 10 day; II-11 - 20 day and III-21 - 30 or 31 day. 


\subsection{Seed Material and Planting}

In the years preceding the main experiment, the plants in vitro of tested cultivars were propagated in the green house to obtain healthy seed material. Obtained in this way, minitubers were kept in storage at a temperature of $3^{\circ} \mathrm{C}$. In the spring they were selected and those of the size 3 - $4 \mathrm{~cm}$ (transverse diameter) were pre-sprouted for 5 weeks and next used for planting. They were planted in 10-liter pots filled with a thin layer of gravel and the soil which was the standard substrate for vegetables. The number of objects (pots) was a total of 198, and each cultivar accounted for 33. Dates of planting took place on April 23 - 24. The pots with plants set on special tables on wheels and were moved outdoor, to a place next to greenhouse. The density of pots set was 4 per $\mathrm{m}^{2}$.

\subsection{Proceeding with Plants during the Growing Season}

Throughout the growing season the plants were carefully tended daily and regularly watered until the level close to optimum. Soil moisture was controlled using the Moisture Meter (PL). Recommended plant protection products were used against diseases and pests. Just before the start of the heat impact, six plants of each cultivar were transferred to a growth chamber for the period of 15 days. Phenological stages of plants of tested cultivars just before the impact of high temperatures in different periods of growing season were presented in Table 2. Conditions in the growth chamber were: photoperiod 15 hours, lighting with Philips SON-T Agro 400W lamps with power supply light at $100-120 \mathrm{Wm}^{-2}$ at $1.5 \mathrm{~m}$. The temperature was maintained at a level established by experiment $\left(32^{\circ} \mathrm{C} / 25^{\circ} \mathrm{C}\right)$. Half of the plants were watered regularly to a level close to the optimum (Favourable Soil Moisture), and the other half were subjected to soil drought by ceasing watering (Soil Drought). After the end of high temperature periods measurements of plant height were performed and then they were transferred to a place next to the greenhouse where further development under conditions close to optimal took place.

\subsection{Final Yield}

Final harvest was performed after full maturity of plants in the Control combination, between August 10 and 19. The total mass and number of tubers per plant and also the mass of tubers with physiological defects were determined. A measure of tolerance of the potato cultivars to high temperature during the growing season was a decrease in yield and number of tubers per plant in relation to the Control combination. The presence of physiological defects in the tubers, mainly second growth was determined as the percentage in the total mass of tubers.
Table 2. Phenological stages of plants of tested cultivars just before the impact of high temperatures in different periods of growing season.

\begin{tabular}{lccc}
\hline Cultivar & Period of $\mathrm{HT}^{*}$ & DAP $^{* *}$ & Phenological stage \\
\hline \multirow{2}{*}{ Irys } & I & $51-65$ & end of flowering \\
& II & $65-79$ & development of fruits \\
& III & $80-94$ & beginning of maturity \\
Cyprian & I & $51-65$ & full flowering \\
& II & $65-79$ & development of fruits \\
& III & $80-94$ & beginning of maturity \\
Adam & I & $51-65$ & no flowering \\
& II & $65-79$ & no fruits \\
& III & $80-94$ & beginning of maturity \\
Irga & I & $51-65$ & no flowering \\
& II & $65-79$ & no fruits \\
& III & $80-94$ & beginning of maturity \\
& I & $51-65$ & full flowering \\
& II & $65-79$ & development of fruits \\
& II & $80-94$ & beginning of maturity \\
& III & $51-65$ & full flowering \\
& I & $65-79$ & development of fruits \\
& beginning of maturity \\
\hline
\end{tabular}

Explanations: "high temperature; ${ }^{* *}$ days after planting. I period of HT- the second half of June; II period of HT-the first half of July; III period of HT - the second half of July.

\subsection{Data Analysis}

The results of the experiments were analyzed with ANOVA using a general linear model of statistics program in SAS Enterprise Guide 4 [18]. Means were separated with Tukey's test at $5 \%$ p-value.

\section{Results and Discussion}

Significant impacts of the tested factors on the height of plants, yield, number of tubers, mass of one tuber and physiological defects of tubers were found (Table 3).

\subsection{Height of Plants Immediately after the Impact of High Temperature}

In the first and second period of heat stress in favourable soil moisture conditions, the plants of all cultivars responded with an increase in the height (Tables 3, 4). The results are consistent with the results of previous studies whereby a temperature higher than optimal intensified 
Table 3. Significance level of tested factors—-from the analysis of variance.

\begin{tabular}{|c|c|c|c|c|c|c|c|}
\hline \multirow{2}{*}{ Characteristics } & \multicolumn{7}{|c|}{ Source of variation } \\
\hline & cultivar & period of stress & kind of stress & year & cultivar x period & cultivar $\mathrm{x}$ kind & period $\mathrm{x}$ kind \\
\hline \multicolumn{8}{|c|}{$\underline{\text { Plants after stresses }}$} \\
\hline Plant height in \% & 0.06 & $<0.0001$ & $<0.0001$ & 0.013 & 0.23 & 0.68 & $<0.0001$ \\
\hline \multicolumn{8}{|c|}{ Final yield in Control } \\
\hline Tuber weight & 0.03 & - & - & 0.0005 & - & - & - \\
\hline Number of tubers & 0.009 & - & - & 0.18 & - & - & - \\
\hline Mass of 1 tuber & 0.04 & - & - & 0.30 & - & - & - \\
\hline \multicolumn{8}{|c|}{$\underline{\text { Final yield in } \%}$} \\
\hline Yield & 0.02 & $<0.0001$ & $<0.0001$ & 0.0004 & 0.14 & 0.26 & 0.01 \\
\hline Number o tubers & $<0.0001$ & 0.16 & 0.003 & 0.99 & 0.93 & 0.81 & 0.19 \\
\hline Mass of 1 tuber & 0.0001 & $<0.0001$ & 0.009 & 0.11 & 0.40 & 0.99 & 0.33 \\
\hline Defects of tubers & $<0.0001$ & 0.003 & 0.02 & 0.10 & 0.004 & 0.59 & 0.01 \\
\hline
\end{tabular}

Explanation: level $\mathrm{P}<0.05$ - differences statistically significant.

Table 4. The height of plants in relation to the Control depending on the period of the impact of high temperature and soil moisture-mean values for tested cultivars (in \%).

\begin{tabular}{ccccc}
\hline \multirow{2}{*}{ Soil moisture } & \multicolumn{4}{c}{ Period of high temperature } \\
\cline { 2 - 5 } & I & II & III & mean \\
\hline FSM $^{*}$ & $151.3 \mathrm{a}$ & $123.8 \mathrm{a}$ & $97.8 \mathrm{a}$ & $124.3 \mathrm{a}$ \\
SD $^{* *}$ & $104.0 \mathrm{~b}$ & $103.3 \mathrm{~b}$ & $97.7 \mathrm{a}$ & $101.7 \mathrm{~b}$ \\
Mean & $127.7 \mathrm{a}$ & $113.6 \mathrm{~b}$ & $97.8 \mathrm{~b}$ & 113.0 \\
I year & & & $117.0 \mathrm{a}$ & \\
II year & & & $110.0 \mathrm{~b}$ & \\
\hline
\end{tabular}

Explanations: ${ }^{*}$ Favourable Soil Moisture; ${ }^{* *}$ Soil Drought; a, b-mean values followed by the same letters in the column of group acc. Tukey's test are not significantly different at the 0.05 level.

development of the aboveground part of plants $[5,7,10$, 19-21]. Our work additionally shows that the increase in the length of the stems was greater the earlier they were influenced by heat. Due to the limited number of plants in the experiment, measurements of the mass of the aboveground part of plants were not performed, because it would have been connected with additional plant liquidation in each of the three periods of stresses.

\subsection{Final Yield}

The final yield of tested cultivars and the number of tubers in Control were relatively high (Table 5). Tuber mass per plant was about twice that in the experiment of Levy [16] but individual tuber weight was similar. This
Table 5. Characteristics of final yield of tested cultivars in the Control.

\begin{tabular}{ccccccc}
\hline Cultivar & \multicolumn{2}{c}{$\begin{array}{c}\text { Mass of tubers } \\
\text { in g/plant }\end{array}$} & $\begin{array}{c}\text { Number of } \\
\text { tubers/plant }\end{array}$ & \multicolumn{2}{c}{$\begin{array}{c}\text { Mass of } \\
1 \text { tuber }\end{array}$} \\
\hline Irys & 1401 & ab & 42.3 & abc & 33.4 & b \\
Cyprian & 1487 & ab & 47.4 & a & 31.3 & b \\
Adam & 1243 & b & 26.4 & c & 47.4 & a \\
Irga & 1515 & a & 44.7 & a & 33.7 & b \\
Zebra & 1540 & a & 46.7 & ab & 34.0 & b \\
Katahdin & 1397 & ab & 29.5 & bc & 47.4 & a \\
Mean & 1430 & & 37.8 & & 37.9 & \\
I year & 1562 & a & 37.5 & a & 39.4 & a \\
II year & 1298 & b & 38.0 & a & 36.4 & a \\
\hline
\end{tabular}

Explanations: a, b-see Table 4.

indicates more intense tuberization under temperate conditions than in a semi-arid Mediterranean climate. In our experience, there were normal differences between cultivars, which are the result of their ability to yielding and physiological seed vigor in a given environment [22]. The higher yield in the first year was probably due to slightly more favourable conditions for potato development.

The high temperature during the growing season had a negative effect on the final yield of tested cultivars (Table 6). The effect was strongest when the high temperature influenced plants in the second half of June (period 
Table 6. The final yield of tested cultivars in relation to the Control depending on cultivar, period of the impact of high temperature and soil moisture (in \%).

\begin{tabular}{|c|c|c|c|c|c|c|c|}
\hline \multirow{3}{*}{ Cultivar } & \multicolumn{6}{|c|}{ Period of high temperature } & \multirow{3}{*}{ Mean } \\
\hline & \multicolumn{2}{|c|}{ I } & \multicolumn{2}{|c|}{ II } & \multicolumn{2}{|c|}{ III } & \\
\hline & FSM & SD & FSM & SD & FSM & SD & \\
\hline Irys & 83.7 & 48.7 & 94.8 & 83.6 & 106.7 & 99.3 & $86.10 \mathrm{ab}$ \\
\hline Cyprian & 84.4 & 75.2 & 99.6 & 85.7 & 104.5 & 89.2 & $89.77 \mathrm{a}$ \\
\hline Adam & 86.4 & 52.7 & 91.9 & 74.4 & 99.1 & 89.8 & $82.38 \mathrm{~b}$ \\
\hline Irga & 84.3 & 47.1 & 99.2 & 70.7 & 97.9 & 88.7 & $81.32 \mathrm{~b}$ \\
\hline Zebra & 90.9 & 73.1 & 97.1 & 80.9 & 103.2 & 91.2 & $89.40 \mathrm{a}$ \\
\hline Katahdin & 87.0 & 74.3 & 92.7 & 84.6 & 103.5 & 88.3 & $88.40 \mathrm{a}$ \\
\hline \multirow{4}{*}{ mean } & $86.2 \mathrm{a}$ & $61.9 \mathrm{~b}$ & $95.9 \mathrm{a}$ & $80.0 \mathrm{~b}$ & $102.5 \mathrm{a}$ & $91.1 \mathrm{a}$ & \\
\hline & \multicolumn{2}{|c|}{$74.05 \mathrm{c}$} & \multicolumn{2}{|c|}{$87.95 \mathrm{~b}$} & \multicolumn{2}{|c|}{$96.80 \mathrm{a}$} & 86.3 \\
\hline & \multicolumn{6}{|c|}{ FSM -94.8 a SD $-77.7 \mathrm{~b}$} & \\
\hline & \multicolumn{6}{|c|}{ I year -82.9 b II year $-89.5 \mathrm{a}$} & \\
\hline
\end{tabular}

Explanations: see Table 4.

I). In this period the decrease in the relative yield was nearly twenty-six percent but the effect was stronger in the case of combined effects of high temperature and drought compared to high temperature under favourable soil moisture conditions. As the time of the impact of high temperature on potato plants was delayed (II and III period), the negative effect on the yield of tubers became weaker, but the differences between the combinations of "favorable soil moisture" and "drought" remained statistically significant. There were no significant differences between cultivars regarding the period of impact of heat stress or soil moisture, which indicates the same direction of the reaction. Among the most tolerant from the viewpoint of decrease in yield were "Cyprian" "Zebra" and "Katahdin". In the study of Levy $[23,24]$ heat stress reduced tuber yields of ten tested potato genotypes from 0 to 96 percent but the experiment was conducted under natural conditions in a semi-arid environment and a comparison was made between two cycles of vegetation, between the spring cycle under favourable climatological conditions and the summer cycle under high temperature conditions. Additionally in his study the seeds were in different physiological ages and vigours. A detailed comparison of the results is therefore difficult but the results of a phytotron experiment conducted by Van Dam et al. [10] clearly indicate that higher temperatures gave lower tuber growth rates irrespective of the length of the photoperiod.

The number of tubers in the final yield of tested cultivars was significantly dependent on the soil moisture during the impact of high temperature (Figure 1). Here

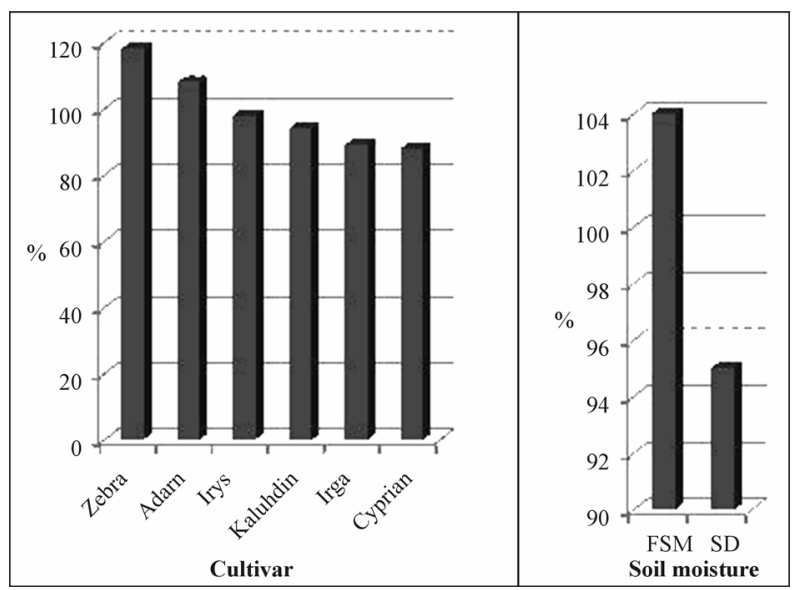

Figure 1. Number of tubers in final yield in $\%$ in relation to Control depending on cultivars and soil moisture-mean values for for the periods of high temperature.

we show that soil moisture favourable for plants led to an increase of the number of tubers. The highest increase was confirmed in cultivars Zebra and Adam. This points to the secondary tuberization in these cultivars. A similar phenomenon was observed by Levy [16] who studied two cultivars, Desiree and Cara, and found that the number of tubers per plant tended to increase in heat treatment in Desiree and to a lesser extent in Cara. In the earlier study of Rykaczewska [12] the increase in the number of tubers from $30 \%$ to $54 \%$ compared to the Control was found and also the presence of tubers chronologically younger. Those studies were performed, however, only with two cultivars with heat stress lasting for three 
weeks.

In the study presented here a highly significant effect of all the examined factors on the tuber size in the yield was found (Table 3, Figure 2).

The physiological defects of tubers were also showed (Table 7, Figure 3). The largest share of these tubers in the final yield occurred in cultivars Irga and Irys and the smallest share in cultivars Zebra, Katahdin and Adam. The earlier high-temperature stress was applied, the greater was the percentage of tubers with physiological defects. Cultivars Irys and Irga remained at a high percent of defects as a result of stress at any time. Results of the experiment obtained by Levy [16] show, however, that a single treatment of high temperatures during early stages of tuber development caused lower the percentage of misshapen tubers. This indicates that studies of this phenomenon with a larger number of cultivars and a more precise determination of the tubers state at the beginning of the impact of heat stress are needed. Here we demonstrated that soil moisture favourable for plant growth in the first periods of heat stress was significantly

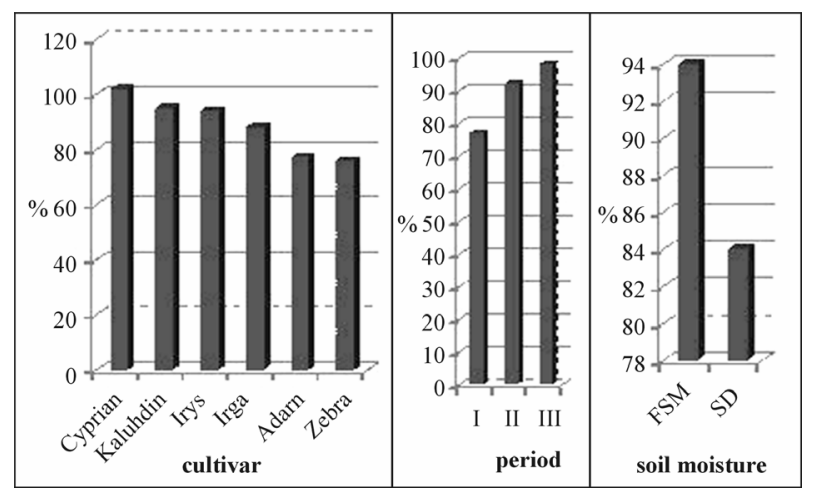

Figure 2. Tuber size in relation to Control depending on cultivar, period of high temperature and soil moisture. more conducive to the physiological defects of tubers like second growth and gemmation than drought.

The significant correlations between the relative height of plants and relative yield, relative tuber size and percentage of tuber with physiological defects confirm the negative, very strong effect of high temperature during growing season on yielding of tested potato cultivars (Table 8).

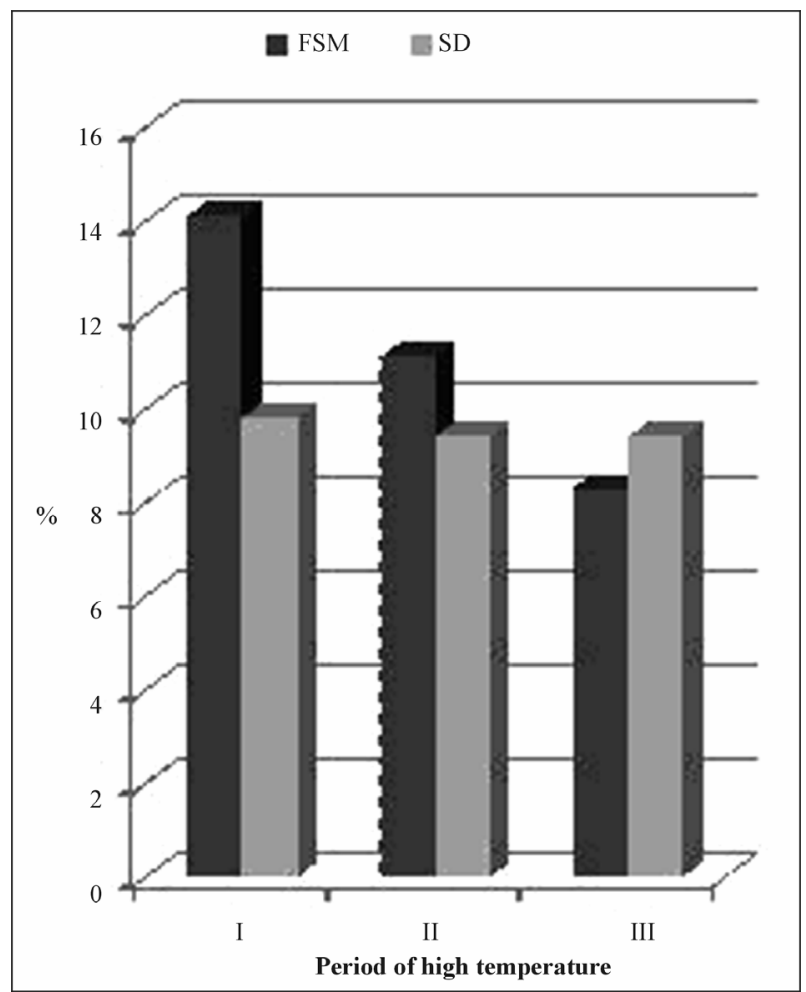

Figure 3. Physiological defects of tubers in final yield depending on the period of high temperature and soil moisture-mean values for cultivars.

Table 7. Percentage of physiological defects of tubers in the final yield depending on cultivar and period of high temperature.

\begin{tabular}{|c|c|c|c|c|c|}
\hline \multirow{3}{*}{$\begin{array}{l}\text { Cultivar } \\
\text { Irys }\end{array}$} & \multicolumn{3}{|c|}{ Period of high temperature } & \multirow{2}{*}{\multicolumn{2}{|c|}{ Mean }} \\
\hline & I & II & III & & \\
\hline & $13.0 \mathrm{ab}$ & $16.3 \mathrm{a}$ & $13.9 \mathrm{ab}$ & 14.4 & $\mathrm{a}$ \\
\hline Cyprian & $11.2 \mathrm{~b}$ & $9.9 \mathrm{bc}$ & $9.5 \mathrm{~b}$ & 10.2 & $\mathrm{~b}$ \\
\hline Adam & $13.1 \mathrm{ab}$ & $5.0 \mathrm{c}$ & $7.8 \mathrm{bc}$ & 8.6 & $\mathrm{bc}$ \\
\hline Irga & $17.7 \mathrm{a}$ & $13.0 \mathrm{~b}$ & $15.9 \mathrm{a}$ & 15.5 & $\mathrm{a}$ \\
\hline Zebra & $6.9 \mathrm{c}$ & $6,2 \mathrm{c}$ & $2.5 \mathrm{c}$ & 5.2 & $\mathrm{c}$ \\
\hline Katahdin & $10.0 \mathrm{~b}$ & $11.4 \mathrm{bc}$ & $3.7 \mathrm{c}$ & 8.3 & $\mathrm{bc}$ \\
\hline mean & $12.0 \mathrm{a}$ & $10.3 \mathrm{ab}$ & $8.9 \mathrm{~b}$ & 10.4 & \\
\hline
\end{tabular}

Explanations: see Table 4. 
Table 8. Correlations between relative height of plants and relative yield, relative number of tubers, relative tuber size, percentage of tubers with physiological defects.

\begin{tabular}{ccc}
\hline Correlation & FSM & SD \\
\hline $\begin{array}{c}\text { Relative height of plants x relative yield } \\
\text { Relative height of plants x relative } \\
\text { number of tubers }\end{array}$ & $-0.996^{* *}$ & $-0.875^{* *}$ \\
$\begin{array}{c}\text { Relative height of plants x relative tuber size } \\
\text { Relative height of plants x \% of } \\
\text { physiological tuber defects }\end{array}$ & $-0.899^{* *}$ & $-0.908^{* *}$ \\
& $+0.999^{* *}$ & $+0.629^{*}$ \\
\hline
\end{tabular}

Explanations: FSM, SD—see Table 4; ${ }^{* *} \mathrm{P}<0.01 ;{ }^{*} \mathrm{P}<0.05$.

\section{Conclusion}

Our studies on the impact of high temperature on the development of potato confirm the view that its productivity is greatly reduced at higher temperatures than the optimum temperatures. It was demonstrated here, however, that potato cultivars' response to high temperature during the growing season is dependent on the growth stage, in which the temperature acts on the plants. The earlier it occurs, the more negative its impact on the growth and yield of potatoes is. Here we show that sustained for two weeks, the combined heat and drought stress which affects potato plants during the flowering period may reduce the yield of susceptible cultivars by over $50 \%$ and more tolerant cultivars by about $25 \%$. It is also a cause of physiological defects of tubers, the mass of which may exceed $10 \%$ of the total yield. Here we show that seemingly mild heat stress acting on the plant for a period of two weeks under favorable soil moisture conditions may cause an increase in the height of the aboveground part of more than $50 \%$ in relation to Control, and a small, just a few percent, decrease in yield. In practice, however, it may be the most harmful due to the presence of secondary tuberization and therefore the appearance in the crop of chronologically and physiologically younger tubers which at the time of harvest can easily be damaged. Another significant disadvantage of the yield produced at high temperatures and favourable soil moisture is numerous physiological defects, which depends on the cultivar can range from a few to tens of percent. In this study the high tolerance of cultivar Katahdin to the heat stress during the growing season has been confirmed. This cultivar was characterized by the relatively low decrease in yield under high temperature stress, the absence of secondary tuberization and a relatively small number of tubers with physiological defects. Our research shows that the relative yield is not the only indicator of potato tolerance to high temperatures during the growing season, but the assessment should also take into account the number of tubers formed as a result of the occurrence of secondary tuberization and also physiological defects. An important criterion may also be the duration of tuber dormancy, but this aspect of the research is undertaken in a separate elaboration.

\section{Acknowledgements}

The author specially thanks for the valuable technical assistance of A. Gajos during the whole period of growing season.

\section{REFERENCES}

[1] A. Wahid, S. Gelani, M. Ashraf and M. R. Foolad, "Heat Tolerance in Plants: An Overview," Environmental and Experimental Botany, Vol. 61, No. 3, 2007, pp. 199-223.

[2] Central Statistical Office, "International Review," In: Consist Statistical Yearbook of Poland, Year LV, Warsaw, 2012, pp. 527, 581. http:/www.stat.gov.pl

[3] Food and Agriculture Organization, "Potato World," 2008. http:/www.potato2008.org

[4] A. J. Haverkort and A. Verhagen, "Climate Change and its Repercussions for the Potato Supply Chain," Potato Research, Vol. 51, No. 3-4, 2008, pp. 223-237. http://dx.doi.org/10.1007/s11540-008-9107-0

[5] K. B. A. Bodlaender, "Influence of Temperature, Radiation and Photoperiod on Development and Yield," In: J. D. Ivins and F. L. Milthorpe, Eds., Growth of the Potato, Butterworths, London, 1963, pp. 199-210.

[6] J. Marinus and K. B. A. Bodlaender, "Response of Some Potato Varieties to Temperature," Potato Research, Vol. 18, No. 2, 1975, pp. 189-204. http://dx.doi.org/10.1007/BF02361722

[7] P. C. Struik, J. Geertsema and C. H. M. G. Custers, "Effect of Shoot, Root and Stolon Temperature on the Development of the Potato ((Solanum tuberosum L) Plant. I. Development of the Haulm," Potato Research, Vol. 32, No. 2, 1989, pp. 133-141.

http://dx.doi.org/10.1007/BF02358225

[8] P. C. Struik, J. Geertsema and C. H. M. G. Custers, "Effect of Shoot, Root and Stolon Temperature on the Development of the Potato ((Solanum tuberosum L) Plant. III. Development of Tubers," Potato Research, Vol. 32, No. 2, 1989, pp. 151-158.

[9] K. Rykaczewska, "Effect of Temperature during Growing Season and Physiological Age of Minitubers on Potato Plant Development and Yield," Bulletin of the Potato Institute, Vol. 42, No. 1, 1993, pp. 39-46.

[10] J. Van Dam, P. L. Kooman and P. C. Struik, "Effects of Temperature and Photoperiod on Early Growth and Final Number of Tubers in Potato (Solanum tuberosum L)," Potato Research, Vol. 39, No. 1, 1996, pp. 51-62. http://dx.doi.org/10.1007/BF02358206

[11] R. Mittler, "Abiotic Stress, the Field Environment and Stress Combination," Trends Plant Science, Vol. 11, No. 1, 2006, pp. 15-19. 
http://dx.doi.org/10.1016/j.tplants.2005.11.002

[12] K. Rykaczewska, "Effect of High Temperature during Vegetation on Potato (Solanum tuberosum L) Yield, Period of Tuber Dormancy and Seed Tuber Yielding Ability. I. Plant Development and Yield," Advances of Agricultural Sciences, Vol. 496, No. 1, 2004, pp. 185-198.

[13] K. Rykaczewska, "Effect of High Temperature during Vegetation on Potato (Solanum tuberosum L.) Yield, Period of Tuber Dormancy and Seed Tuber Yielding Ability. II. Tuber Dormancy Duration," Advances of Agricultural Sciences, Vol. 496, No. 1, 2004, pp. 199-206.

[14] K. Rykaczewska, "Effect of High Temperature during Vegetation on Potato (Solanum tuberosum L) Yield, Period of Tuber Dormancy and Seed Tuber Yielding Ability. III. Value of Seed Tuber Yielding," Advances of Agricultural Sciences, Vol. 496, No. 1, 2004, pp. 207-216.

[15] L. De Temmerman, A. Hacour and M. Guns, "Changing Climate and Potential Impacts on Potato Yield and Quality 'CHIP': Introduction, Aims and Methodology," European Journal of Agronomy, Vol. 17, No. 4, 2002, pp. 233242. http://dx.doi.org/10.1016/S1161-0301(02)00063-1

[16] D. Levy "The Response of Potatoes to a Single Transient Heat or Drought Stress Imposed at Different Stages of Tuber Growth," Potato Research, Vol. 28, No. 4, 1985, pp. 415-424. http://dx.doi.org/10.1007/BF02357516

[17] European Potato Cultivars Database, 2008. http:/www. Europotato.org

[18] SAS Institute Inc., "SAS. 9.1. Companion for Windows," SAS Publishing, SAS Institute Inc., Cary, 2004.
[19] G. R. Benoit, C. D. Stanley, W. J. Grant and D. B. Torrey, "Potato Top Growth as Influenced by Temperatures," American Potato Journal, Vol. 60, No. 7, 1983, pp. 489501. http://dx.doi.org/10.1007/BF02877320

[20] H. Gawrońska, R. B. Dwelle and M. K. Thornton, "Influence of Heat Stress on Dry Matter Production and Photoassimilate Partitioning by Four Potato Clones," American Potato Journal, Vol. 69, No. 10, 1992, pp. 653665. http://dx.doi.org/10.1007/BF02852678

[21] P. L. Kooman and A. J. Haverkort, "Modeling Development and Growth of the Potato Crop Influenced by Temperature and Daylength," In: A. J. Haverkort and D. K. L. MacKerron, Eds., Potato Ecology and Modeling of Crop under Conditions Limiting Growth, Kluwer Academic Publishers, Dordrecht, 1995, pp. 41-59.

[22] K. Rykaczewska, "Assessment of Potato Mother Tubers Vigour Using the Method of Accelerated Geing," Plant Production Science, Vol. 16, No. 2, 2013, pp. 171-182.

[23] D. Levy, "Genotype Variation in the Response of Potatoes (Solanum tuberosum L.) to High Ambient Temperatures and Water Deficit," Field Crop Research, Vol. 15, No. 1, 1986, pp. 85-96. http://dx.doi.org/10.1016/0378-4290(86)90103-6

[24] D. Levy, "Tuber Yield and Tuber Quality of Several Potato Cultivars as Affected by Seasonal High Temperature and by Water Deficit in a Semi-Arid Environment," Potato Research, Vol. 29, No. 1, 1986, pp. 95-107. http://dx.doi.org/10.1007/BF02361984 